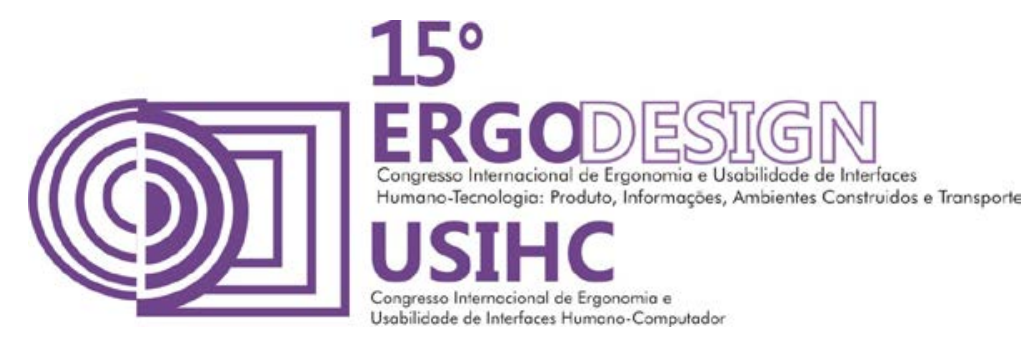

\title{
DESIGN PARA ACESSIBILIDADE: ESTUDO E DESENVOLVIMENTO DE UMA CABINE DE AUDIOMETRIA VOLTADA AOS PARAPLÉGICOS E TETRAPLÉGICOS
}

\section{DESIGN FOR ACCESSIBILITY: DESIGN AND DEVELOPMENT OF A DIRECTED TO CABIN AUDIOMETRY PARAPLEGICS AND QUADRIPLEGICS}

\author{
ZAMBON, Sara Alonso (1); \\ BORTOLIN, Anderson Ricardo (2); \\ FERNANDES, Fabiane Rodrigues (3) \\ (1) FAAL, Bacharel em Design de Produto \\ e-mail: sara.zambon@hotmail.com \\ (2) FAAL, Prof. MSc. do Curso de Design \\ e-mail: arbortolin@live.com \\ (3) FAAL, Prof. MSc. do Curso de Design / PPGDesign - UNESP Bauru \\ e-mail: fabyfernandes@gmail.com
}

\begin{abstract}
RESUMO
O objetivo de tornar a cabine de audiometria acessível para pessoas cadeirantes é oferecer a igualdade no atendimento, para esse fim foram utilizados o Design Universal e a Acessibilidade contendo ergonomia e medidas antropométricas, e estudos analisados sobre deficiência física em relação à paraplegia e tetraplegia, com a finalidade de trazer conforto e segurança apropriados no produto, assim respeitando as limitações aplicadas no mesmo. Por fim, para a execução da maquete da cabine de audiometria foi usada a metodologia de Lobäch (2001) que constitui em quatro fases sendo: Preparação, geração, avaliação e realização, desenvolvendo assim um projeto adequado e implementação da maquete respeitando as normas da Associação Brasileira de Normas Técnicas (ABNT: NBR 9050) aplicada na acessibilidade.
\end{abstract}

Palavras-chave: Design, acessibilidade, Audiometria

\begin{abstract}
The goal to make the cabin accessible for wheelchair people audiometry is to provide equal service for this purpose we used the Universal Design and Accessibility containing ergonomics and anthropometric measurements, and analyzed studies on disability in relation to paraplegia and quadriplegia, with in order to bring comfort and appropriate in product safety, respecting the limitations imposed on it. Finally, to
\end{abstract}




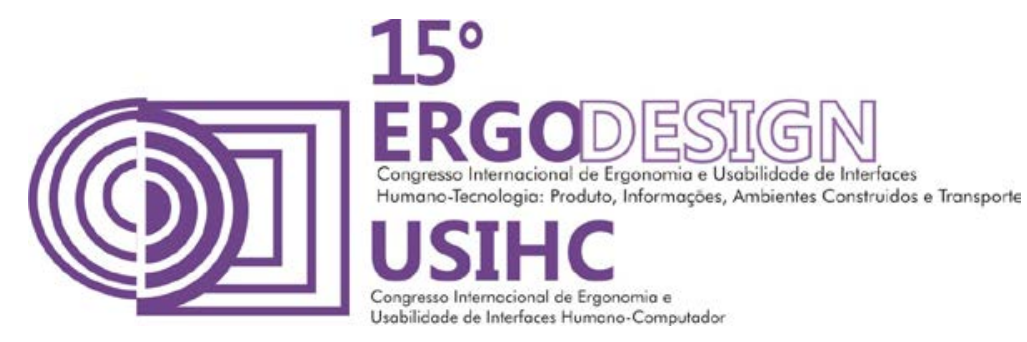

implement the model of audiometry cabin was used to Lobach methodology (2001) which is in four stages as follows: Preparation, generation, evaluation and implementation, developing a suitable design and model implementation respecting the rules of the Association Brazilian Technical Standards (ABNT: NBR 9050) applied to the accessibility.

Keywords: Design, acessibility, audiometry

\section{INTRODUÇÃO}

Cabine significa "pequeno compartimento" e acústica significa "parte física que trata do som; propagação do som em um local" (BUENO, 2000). Portanto, a cabine acústica é um espaço pequeno e fechado semelhante ao cubículo, tendo a finalidade de reduzir os ruídos externos para não haver a interferência de sons internos quando estão em exames audiométricos. E são instaladas e operadas pelos profissionais como fonoaudiólogos, nos consultórios de fonoaudiologia ou nas clínicas especializadas no ramo de saúde auditiva ou nos hospitais ou nas empresas onde necessitam da mesma ao realizar avaliações periódicas dos funcionários.

Os principais equipamentos audiológicos adotados para a cabine são, de acordo com Leonor (2008) e Centro Auditivo (2013), o audiômetro, o imitanciômetro os fones de ouvido e a pera de resposta.

Finalmente, ao tornar a cabine de audiometria em acessibilidade para atender os deficientes físicos como os paraplégicos e tetraplégicos, utilizam - se o Desenho Universal, que é definido como se destinar a qualquer pessoa e por ser fundamental para tornar possível a realização das ações essenciais praticadas na vida cotidiana, o que na verdade é uma consolidação dos pressupostos dos direitos humanos, de acordo com a Cambiaghi (2007) e a Acessibilidade, que é definida como a possibilidade e condição de alcance, percepção e entendimento para a utilização com segurança e autonomia, conforme a ABNT1: NBR 90502 (2004), ou seja, ASSOCIAÇÃO BRASILEIRA DE NORMAS TÉCNICAS, NBR 9050: 2004.

Para Mendes (2013), há uma baixa quantidade de cabines audiométricas acessíveis ou parcialmente acessíveis por haver o improviso da rampa específica de acesso e portas com as dimensões inadequadas para aqueles que utilizam a cadeira de rodas. Por este motivo, apresenta que a acessibilidade é essencial para aqueles que possuem alguma(s) deficiência(s), assim adquirindo os direitos iguais garantidos por lei às pessoas normais e tornar este produto necessário e apropriado para as pessoas com alguma(s) deficiência(s), principalmente os cadeirantes por haver maiores problemas ergonômicos.

Quanto ao espaço interno, há suportes inadequados, em questões ergonômicas, para os fones de ouvido, já que algumas vezes os pacientes possuem certa dificuldade ao pegá-los para usar quando o examinador pede por haver a distância de comprimento e de altura entre o suporte e o cadeirante. Também o ambiente interno, sendo que a maioria das cabines possuem a planta

\footnotetext{
${ }^{1}$ ABNT - Associação Brasileira de Normas Técnicas.

${ }^{2}$ NBR 9050 - Acessibilidade a edificações, mobiliário, espaços e equipamentos.
} 


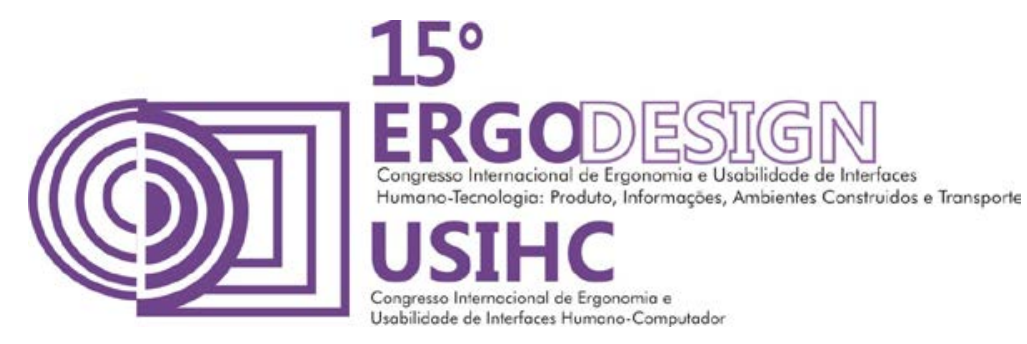

de dimensão inadequada o que impede a circulação livre com cadeira de rodas, desrespeitando a antropometria do deficiente físico.

Em suma, este projeto é voltado para as pessoas com necessidades especiais, especialmente as cadeirantes, com objetivo de facilitar a entrada e melhorar o espaço interno e externo atendendo as normas ABNT aplicadas na acessibilidade de pessoas com deficiências a edificações, espaço, mobiliário e equipamentos urbanos; e as medidas antropométricas ergonômicas e as normas ergonômicas.

\section{FUNDAMENTAÇÃO TEÓRICA}

\subsection{Desenho Universal}

O desenho universal tem sua definição como "se destinar a qualquer pessoa e por ser fundamental para tornar possível a realização das ações essências praticadas na vida cotidiana, o que na verdade é uma consolidação dos pressupostos dos direitos humanos" (CAMBIAGHI, 2007). Em outras palavras, o desenho universal projeta os produtos, os espaços dos edifícios, dos locais públicos e urbanos que sejam adaptáveis e acessíveis a todas as pessoas, incluindo àquelas que possuem necessidades especiais. Assim facilita as atividades cotidianas realizadas pelas pessoas com deficiência e melhora a qualidade de serviço delas também, com isso garante os mesmos direitos humanos garantidos por lei que outras que não possuem necessidades especiais, de acordo com a Cambiaghi (2007) e Carletto e Cambiaghi (2008). Embora, muitas vezes, focado na construção, esse conceito também serve as áreas de produto, que também trabalham com os objetos/peças que atendam às necessidades e os requisitos das pessoas, aplicando usabilidade.

\section{$2.2 \quad$ Acessibilidade}

A acessibilidade significa "possibilidade e condição de alcance, percepção e entendimento para a utilização com segurança e autonomia de edificações, espaço, mobiliário, equipamento urbano" (NBR 9050, 2004). "Acessibilidade é a possibilidade de acesso a um lugar" (MORAES, 2004). Em outras palavras, ela dá oportunidades para as pessoas com deficiência como terem acesso aos espaços, terem os direitos iguais garantidos por lei como aquelas que não possuem a mesma, elas terem sua segurança nos espaços internos e urbanos até o acesso ao transporte sem as diferenças.

As normas de acessibilidade visam proporcionar ao maior número possível de pessoas, independente de idade, estatura ou limitação de mobilidade ou percepção, a utilização de maneira autônoma e segura do ambiente, edificações, mobiliário, equipamentos urbanos e elementos, conforme a Associação Brasileira de Normas Técnicas, NBR 9050: 2004. E, segundo os dados de IBGE (2010), com a crescente população com deficiência (14,5\% para $23,9 \%$ da população com alguma deficiência), aumenta a necessidade de acessibilidade aplicada nos espaços e nos produtos, para que atenda aos requisitos fundamentais das pessoas com necessidades especiais. Ou para melhor simplificação, assegura ao criar os espaços ou/e produtos cumprindo as normas técnicas e leis da acessibilidade criadas pela Associação Brasileira garantindo igualdade e respeito a todos. 


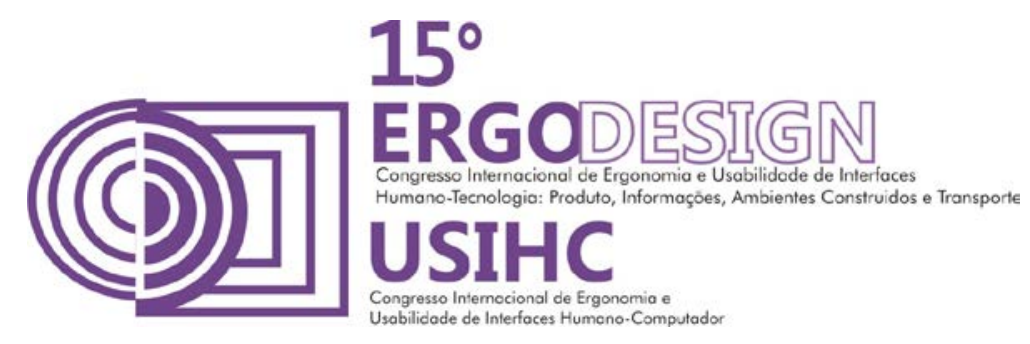

\subsection{Ergonomia}

A ergonomia dedica a relação entre o ser humano e a máquina ou/e tarefa para evitar os prejuízos na saúde humana como a fadiga, o ferimento em qualquer parte do corpo humano, e com objetivo de trazer a segurança, o conforto e usabilidade aos homens na área de trabalho, porém não só no trabalho, também nos produtos. Como dizem o Dul e Weerdmeester (2004), as condições de insegurança, insalubridade, desconforto e ineficiência são eliminadas adaptando-as às capacidades e limitações físicas e psicológicas do homem.

Quanto a antropometria, define como "o estudo da forma e do tamanho do corpo humano" (TILLEY; ASSOCIATES, 2005). Ela estuda as medidas e as proporções humanas para projetar as dimensões adequadas dos ambientes, dos produtos evitando as falhas possíveis ao causar os desconfortos. Por exemplo, instalar um elevador de tamanho adequado para os cadeirantes ou projetar uma pia para as pequenas crianças.

Sendo que estas disciplinas - Ergonomia e Antropometria - são fundamentais para definir o dimensionamento do espaço e dos produtos para atender a medidas antropométricas e as normas ergonômicas da cadeira de rodas, além de trazer a usabilidade e o conforto para 0 cadeirante.

Portanto a acessibilidade é ligada às Ergonomia e Antropometria, pois com elas formam o conteúdo adequado com fatores corretos, assim evita as maiores falhas e os altos prejuízos ao projetar algo como o espaço ou produto para as pessoas, especialmente para aquelas que possuem as necessidades especiais.

\subsection{Deficiência Física}

Para o Instituto Benjamim Constant (IBC, 2005), a deficiência significa que apresente, em caráter permanente, perdas ou reduções de sua estrutura, ou função anatômica, fisiológica, psicológica ou mental, que geram incapacidade para certas atividades, dentro do padrão considerado normal para o ser humano. Há diversos tipos de deficiência como: auditiva, física, intelectual e visual. E para cada tipo, há "subtipos", por exemplo, a visão do indivíduo pode ser total ou parcial ou a perda de audição bilateral ou unilateral. A pessoa também pode possuir mais de uma deficiência, dando o nome de deficiência múltipla. A mobilidade reduzida é compreendida "como qualquer pessoa cuja mobilidade está condicionada devido ao envelhecimento, à maternidade, a uma deficiência motora e/ou cognitiva e/ou a qualquer outra causa que afete a sua mobilidade e requeira adaptação especial às suas necessidades" (ASSOCIAÇÃO SALVADOR, 2011).

A deficiência física possui "alteração completa ou parcial de um ou mais segmentos do corpo humano" (IBDD, 2009). Quer dizer que alguma parte da pessoa, podendo ser completa ou parcial, não possui um bom funcionamento ou a falta de funcionamento para executar as funções.

Com isso, pode ter como consequência a ostomia ${ }^{3}$, amputação ou ausência de membro, nanismo ${ }^{4}$, membros com deformidade congênita ou adquirida, exceto as deformidades estéticas

\footnotetext{
${ }^{3}$ Ostomia: É uma cirurgia para construção de um novo trajeto para saída das fezes ou da urina. (OSTOMIZADOS, 2007).
} 


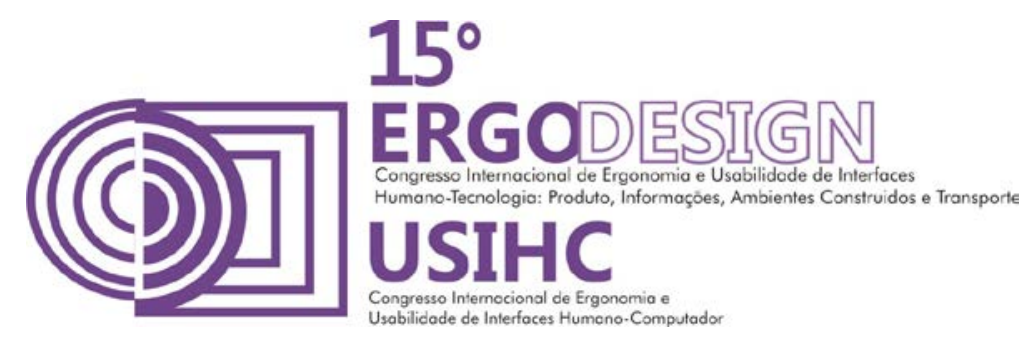

e as que não produzam dificuldades para o desempenho de funções, cita IBDD (2009). Além disso, ainda possui diversas classificações dela, tendo congênita ${ }^{5}$ ou adquirida, segundo IBC (2005):

- Paraplegia: perda de todas das funções motoras. Em outras palavras, o indivíduo não tem os movimentos de cintura para baixo basicamente.

- Paraparesia: perda parcial das funções motoras dos membros inferiores.

- Monoplegia: perda parcial das funções motoras de um só (podendo ser superior ou inferior).

- Monoparesia: perda parcial das funções motoras de um só membro (podendo ser superior ou inferior).

- Tetraplegia: perda total das funções motoras dos membros superiores e inferiores. Ou seja, o indivíduo não possui os movimentos de pescoço para baixo basicamente.

- Triplegia: perda parcial das funções motoras dos membros superiores e inferiores.

- Triparesia: perda total das funções motoras em três membros.

- Hemiplegia: perda total das funções motoras de um hemisfério do corpo (direito ou esquerdo).

- Hemiparesia: Perda parcial das funções motoras de um hemisfério do corpo (direito ou esquerdo).

\subsection{Cabine de Audiometria}

A Cabine significa "pequeno compartimento". Há determinados tipos deste produto como cabine de avião - espaço reservado ao piloto -, compartimento telefônico e entre outras.

Acústica significa "parte física que trata do som; propagação do som em um local" (BUENO, 2000). Já para Costa (2003), o som é resultado das vibrações dos corpos elásticos, quando essas vibrações se verificam em determinados limites de frequências. Em outras palavras, 0 som é um tom emitido por alguma máquina ou pelo ser vivo ou pela natureza em qualquer lugar onde haja o ar, já que este fenômeno acústico necessita da atmosfera tornando este audível aos seres humanos e seres animais.

Portanto, a cabine acústica é um ambiente fechado pequeno com o objetivo de redução de ruídos, logo não se ouve os sons externos da cabine, evitando a confusão sonora interna.

A cabine de audiometria (figura 1) é um espaço onde realiza os exames audiométricos o que não pode haver a interferência sonora, e com isso obtém a confiabilidade nos testes de audição. O Conselhos Federal e Regionais de Fonoaudiologia (2010) cita: "os níveis de pressão sonora do ruído ambiente em uma cabina audiométrica ou em uma sala de testes audiológicos

\footnotetext{
${ }^{4}$ Nanismo: s.m. Qualidade de anão. (BUENO, 2000).

${ }^{5}$ Congênito: adj. Gerado ao mesmo tempo tempo; nascido com o indivíduo; (BUENO, 2000).
} 


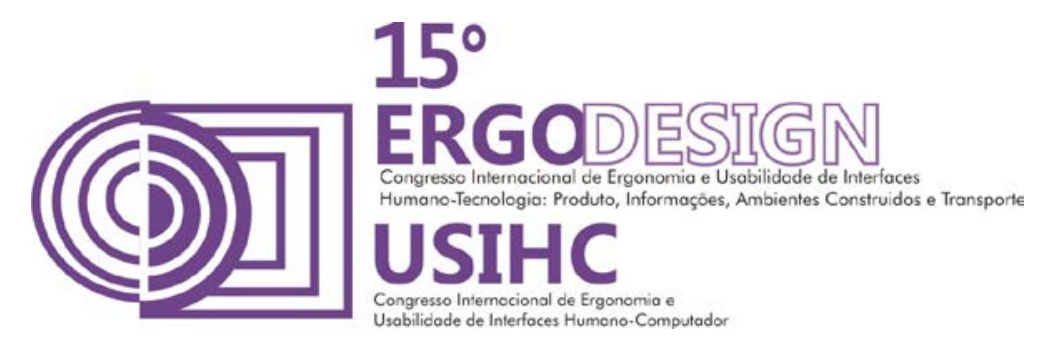

devem ser controlados de modo a evitar o mascaramento de tons de teste e fornecer resultados fidedignos ${ }^{6} . "$

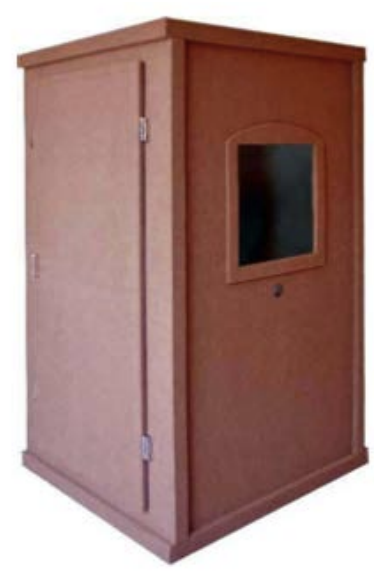

Figura 1 - Cabine acústica.

Fonte: LEONOR, 2008.

\section{DESENVOLVIMENTO}

\subsection{Metodologia}

O projeto é caracterizado como exploratório, pois através de coletas de dados a respeito do usuário com deficiência e do produto escolhido (cabine audiométrica) que necessita de melhoramento, desenvolveu-se uma maquete de possíveis melhorias relacionadas a esse produto. O projeto de divide em dois momentos: coleta de informações acerca do público-alvo e do mercado, ou seja, análise dos produtos existentes e, posteriormente, o desenvolvimento do novo produto com base na metodologia de Lobach (2001).

\subsubsection{Análise de similares}

Para análise de similares alguns produtos existentes no mercado foram analisados, como: os modelos AL-80 e AL-150 do site audiometrodigital.com.br; os modelos teuto do site centroauditivo.com.br; modelo S40 do site sibelmed.mesop.pt; modelo C30 do site quirumed.com; modelo VSA 40E do site vibrashop.com.br;

\footnotetext{
${ }^{6}$ Fidedigno: adj. Digno de fé (BUENO, 2000)
} 


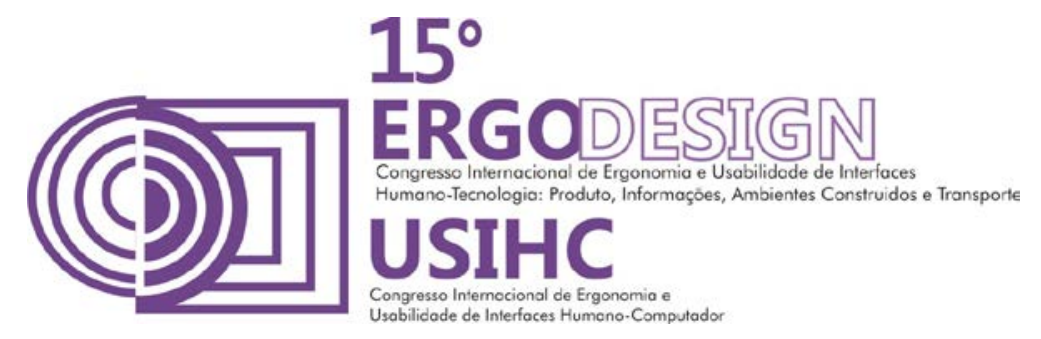

Ao analisar as cabines similares, foi observado o problema principal em relação às dimensões como $0,8 \mathrm{~m}$ de largura $\times 0,9 \mathrm{~m}$ de comprimento ou 1,50 $\mathrm{m}$ de largura $\times 1,50 \mathrm{~m}$ de comprimento correspondem à maioria das cabines de audiometria, que são pequenas para acomodar usuário da cadeira de rodas, pois de acordo com Associação Brasileira de Normas Técnicas Brasileiras - NBR9050 (2004), a cadeira de rodas possui o giro médio - rotação de $360^{\circ}$ - de 1,50m e dois giros parciais - rotação de $90^{\circ}$ e $180^{\circ}$ na área para manobra sem deslocamento (figura 2):

- Para rotação de 90: $1,20 \mathrm{~m}$ x 1,20 m;

- Para rotação de $180^{\circ}: 1,50 \mathrm{~m}$ x 1,20 m;

- Para rotação de $360^{\circ}$ : diâmetro de 1,50 m.

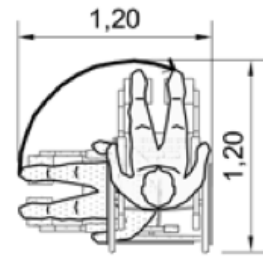

a) Rotação de $90^{\circ}$

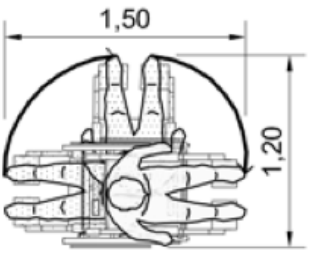

b) Rotação de $180^{\circ}$

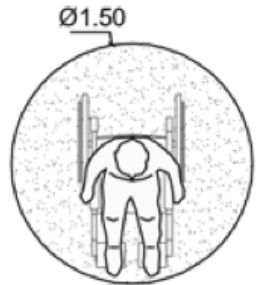

c) Rotação de $360^{\circ}$

Figura 2 - Área para manobra sem deslocamento.

Fonte: Associação Brasileira de Normas Técnicas Brasileiras - NBR 9050, 2013.

Quanto à manobra de cadeiras de rodas com deslocamento (figura 3), exige, de acordo com Associação Brasileira de Normas Técnicas Brasileiras - NBR9050 (2004):

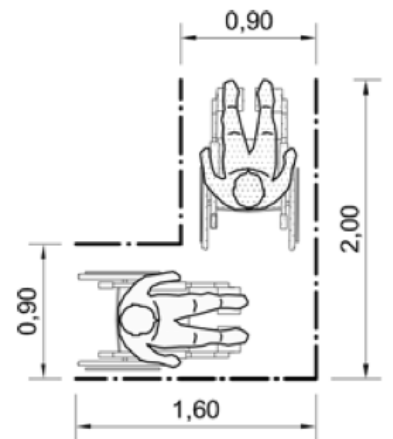

a) Deslocamento de $90^{\circ}$

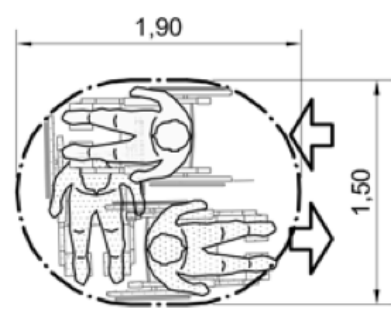

b) Deslocamento de $180^{\circ}$

Figura 3 - Manobra de cadeiras de rodas com deslocamento.

Fonte: Associação Brasileira de Normas Técnicas Brasileiras - NBR 9050, 2013.

Portanto, para trazer conforto aos cadeirantes, a melhor solução é a partir de 2,00 m de largura e 1,70 m de comprimento em dimensões internas para cabine audiométrica. 


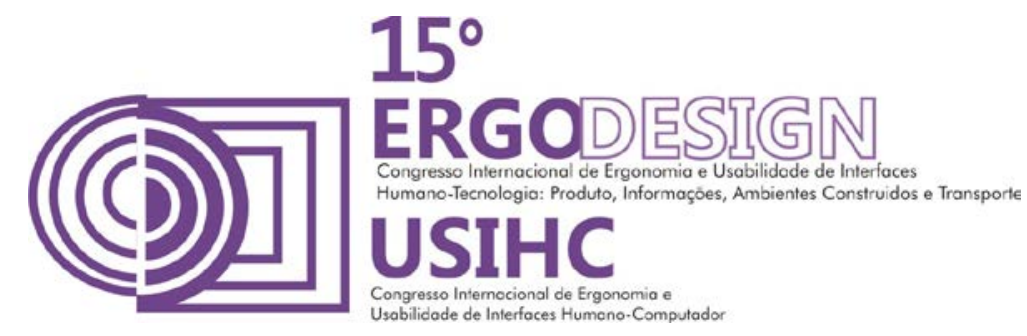

Além disso, mesmo que tivesse rampa separada para as cabines para ser utilizada pelo cadeirante, não é eficaz porque pode haver um encaixe mal feito ficando muito afastada ou mal posicionada, impedindo os usuários de cadeira de rodas. Por este motivo, seria melhor ter uma rampa fixada à cabine.

Há outros problemas menores, porém essenciais, como mesa embutida com ao lado externo da cabine e visor pequeno, os manejos da porta. Para trazer a funcionalidade e o conforto, utilizarão os estudos principais de Desenho Universal e Ergonomia melhorando a qualidade destes itens.

\subsubsection{Desenvolvimento do produto}

Seguindo o método de Löbach (2001), o ponto de partida é o Design Industrial. Tendo este tipo de procedimentos, há quatro fases diferentes a ser completadas para o desenvolvimento de produto adequado: Fase de preparação; Fase de geração; Fase de avaliação; Fase de realização.

\subsubsection{Fase de preparação}

Para desenvolver o projeto de cabine de audiometria acessível para os cadeirantes foi preciso determinar público alvo e após isso realizar as pesquisas relevantes ao tema de acordo a figura 4.

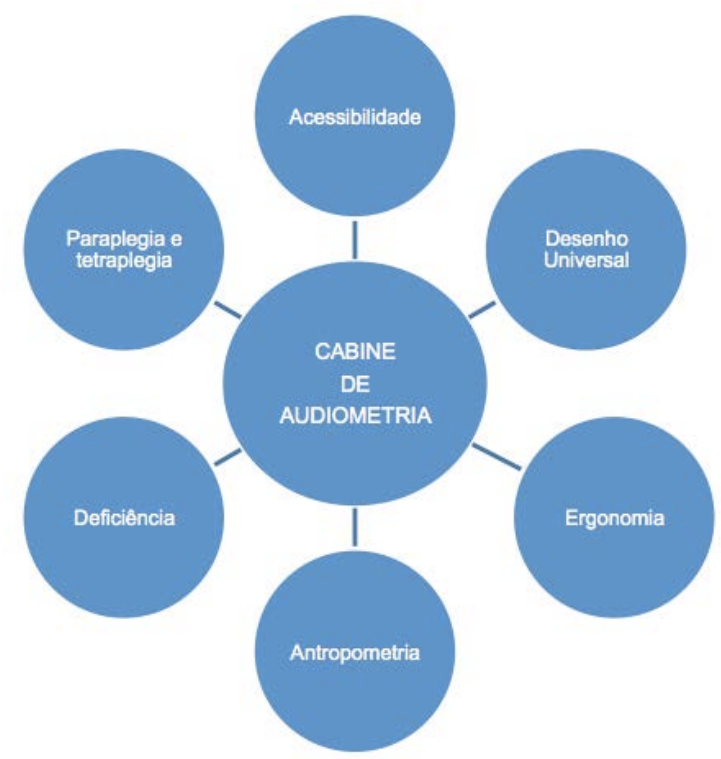

Figura 4 - Assuntos relevantes ao levantamento de dados sobre Cabines Audiométricas Fonte: do Autor, 2013.

Ainda, principalmente, a "análise de similares, de função (funções práticas), estrutural, da relação social, patentes, legislação e norma e exigências para com o novo produto, 


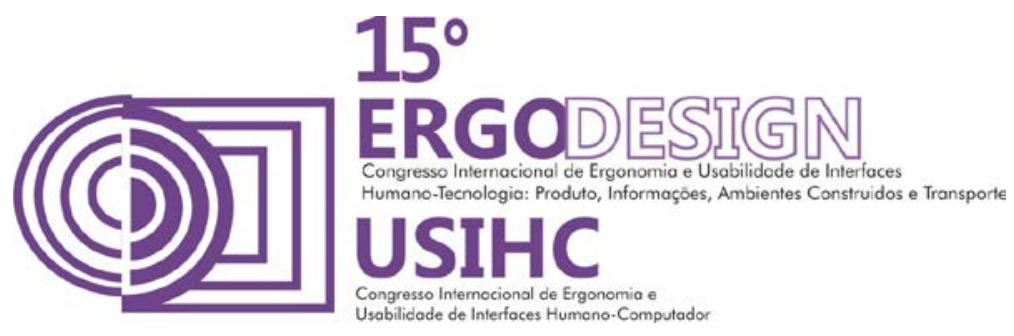

desenvolvimento histórico, análise funcional, análise de materiais" (LÖBACH, 2001) são realizadas durante o desenvolvimento do produto, com a finalidade de compreender, de forma melhor, o funcionamento de cabine de audiometria para que fosse executada adequadamente ao chegar a produção dela.

\subsubsection{Fase de geração}

$\mathrm{Na}$ segunda fase, o Löbach (2001) destaca a fase da produção de ideias baseando-se nas análises realizadas. Ainda descreve que as soluções para problemas de Design podem ser buscadas, usando-se uma solução viável para o problema.

Ainda existem dois métodos distintos para solucionar os problemas e também podem ser apresentados de forma mista, de acordo com Löbach (2001): tentativa e erro e aguardar a inspiração.

Assim que, para alternativas de solução, usa-se o método de "tentativa e erro" para resolver problemas envolvidos em acessibilidade da cabine de audiometria com o uso de Desenho Universal, Antropometria e Ergonomia, realizando os esboços e analisando os desenhos deste produto para que o desenvolvimento do projeto seja apropriado para os usuários de cadeira de rodas.

\subsubsection{Fase de avaliação}

$\mathrm{Na}$ terceira fase, há entre as alternativas elaboradas pode-se encontrar agora qual é a solução mais plausível se comparada com os critérios elaborados previamente, de acordo com Löbach (2001).

Então, ao escolher a "melhor solução da alternativa" que atenda às necessidades entre cabine de audiometria e cadeirantes em termos de acessibilidade, e quanto à "incorporação das características ao novo produto" (LÖBACH, 2001), no quesito financeiro, são realizadas as pesquisas sobre o material e construção (montagem) para atingir o custo razoável, desde que tenha uma boa qualidade para que o produto seja durável, e quanto à estética, é utilizada por último, a fim de ter o mesmo de alta qualidade.

\subsubsection{Fase de realização}

Enfim, a quarta e última fase, o Löbach (2001) explica:

O último passo do processo de design é a materialização da alternativa escolhida. Ela deve ser revista mais uma vez, retocada e aperfeiçoada. Muitas vezes, ela não é nenhuma das alternativas, isoladamente, mas uma combinação das características boas encontradas em várias alternativas. A melhor alternativa apresentada na forma de um produto industrial, se converte então - através de diversas etapas - em um protótipo e cabeça de série. (LÖBACH, 2001).

\section{RESULTADO}

Foram criadas seis alternativas para a cabine, sendo que a sexta alternativa (figura 5) foi escolhida por ter maiores vantagens em relação à acessibilidade atendida para respeitar as 


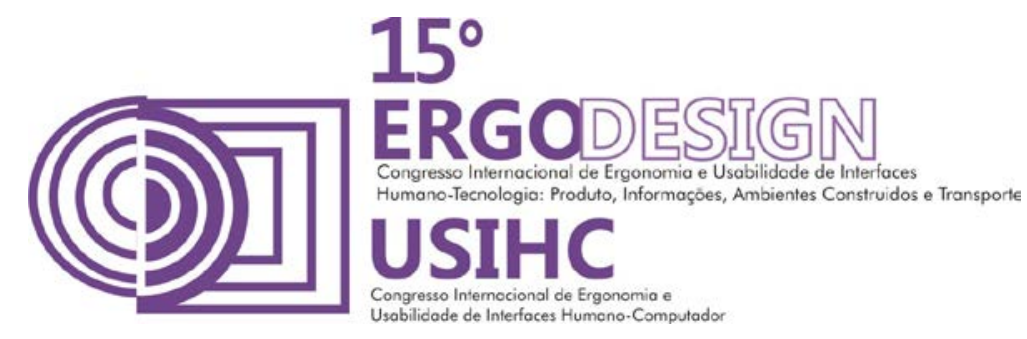

necessidades de usuários de cadeira de rodas, fora aqueles que necessitam de ajuda como idosos e aqueles que não possuem as necessidades especiais.

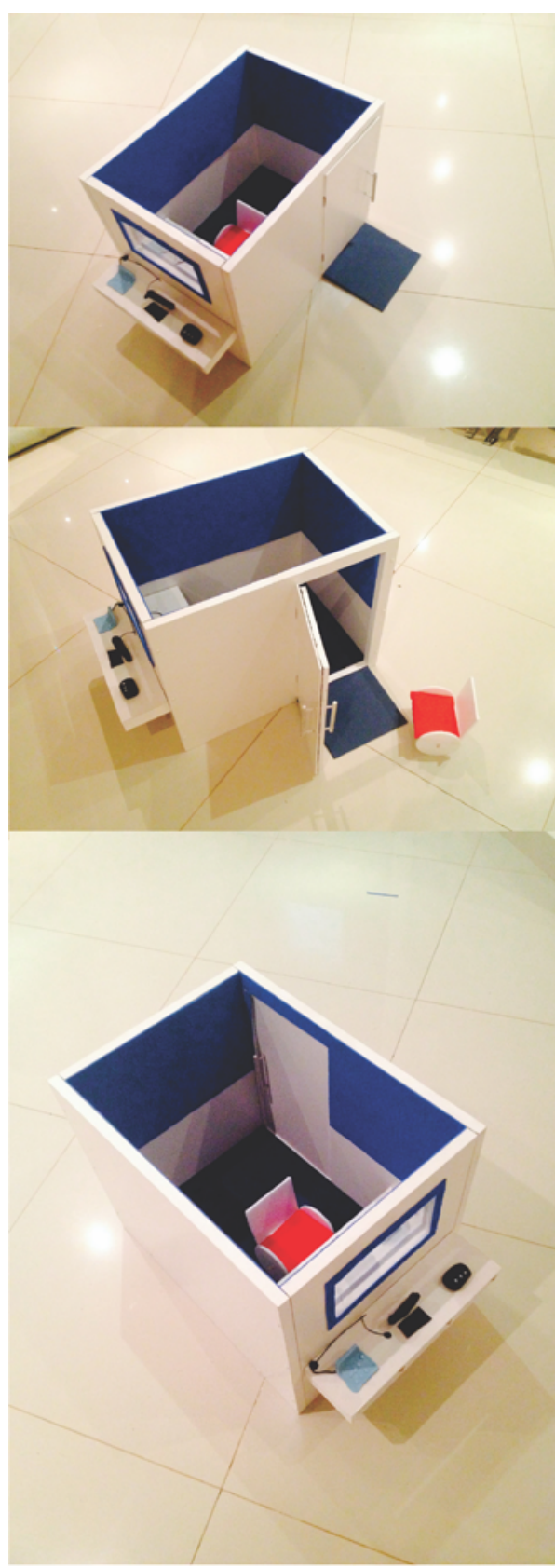

1. ACÚSTICA: Para isolar a cabine de audiometria, utiliza a lã de rocha por ser excelente isolamento acústico e térmico, pois apresenta-se como um material com uma elevada eficácia parente os desafios mais exigentes no que diz respeito à absorção acústica, cumprindo simultaneamente as exigências térmicas mais rigorosas

2. VISOR: deve ser dois ou três vidros com $8 \mathrm{~mm}$ ou mais de espessura, na posição diagonal, devem ter entre $50 \mathrm{~cm}$ ou mais de altura e largura, sua vedação deve ser perfeita e deve ficar um pouco acima da mesa onde ficam os equipamentos, evitando assim dar pistas aos pacientes com relação ao manuseio do audiômetro (ACÚSTICA ORLANDI, 2013). Segundo o site de Nivel Som (2013), a Janela Acústica [...] é indicada para proporcionar conforto termo-acústico para [...], estúdios de gravações, [...], salas acústicas em áreas de produção, entre outros.

3. REVESTIMENTO INTERNO e EXTERNO: espuma de poliuretano poliéter auto-extinguivel, [...], leva em sua formulação aditivos acaricidas, bactericidas e fungicidas que evitam a proliferação dos microorganismos, protegendo o revestimento contra bolores, mofo e odores provenientes de bactérias. O principal diferencial a aplicação sobre a espuma de uma película de PVC, permitindo que a superfície do revestimento exposta seja facilmente limpa com água e sabão para melhor higienização. Também possui superfície lisa para evitar o acúmulo de sujeira e facilitar a limpeza (VIBRASOM, 2013).

4. ILUMINAÇÃO: As lâmpadas utilizadas são as fluorescentes compactas por haver a luz fria.

5. ESTRUTURA: Para estrutura da cabine de audiometria como suporte para paredes e base, utiliza a chapa de o baixo aço carbono sendo AISI 1020

6. PORTA E MAÇANETA: A porta possui basicamente os mesmos materiais específicos citados como estrutura de chapa de baixo aço carbono, isolamento acústico e térmico de lã de rocha, revestimento externo de tinta antiferruginosa e tinta Epóxi nas paredes e piso antiderrapante e revestimento interno de Sonique Aseptic ou Sonique Wave. Quanto à maçaneta, possui dois fechos pressão e um puxador largo para facilitar o manejo, sendo ainda possivel também abrir por dentro da cabine. Por fim, à dobradiça com mola e rolamentos. Há duas unidades dela instaladas na porta.

\section{A PROPOSTA}

Apresenta um visor de dimensões maiores, duas gavetas na mesa embutida para o executante do teste, rampa fixada e porta comum com maçaneta adequada, ou seja, manejo fácil para ser utilizado ao abri-la. Dentro existe uma mesa para o paciente que estará fazendo o teste com uma gaveta para guardar os equipamentos internos.

Figura 5 - Proposta final da Cabine Audiométrica

Fonte: do Autor, 2013. 


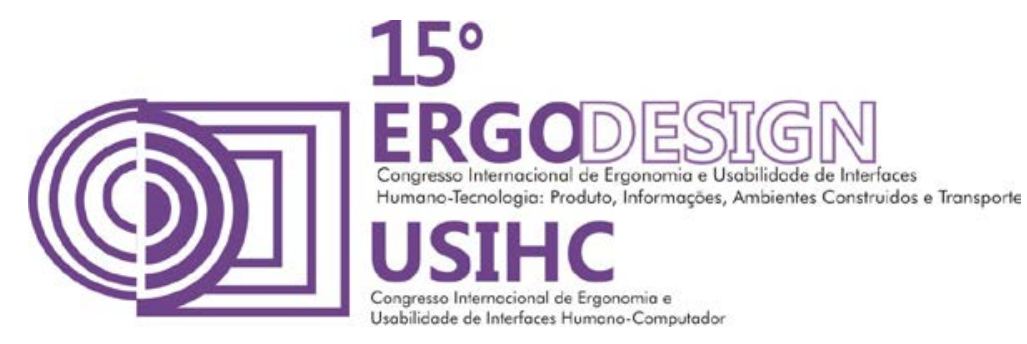

\section{CONCLUSÃO}

Compreender a funcionalidade da cabine de audiometria em geral foi fundamentalmente para o projeto, descobrir suas deficiências/ausência, a planta de espaço, os equipamentos e também o funcionamento de operação na cabine, atingindo um dos objetivos deste projeto. Para que outro dos objetivos fosse atingido foi necessário realizar pesquisas sobre deficiência física, em especial a paraplegia e tetraplegia, para que houvesse um entendimento do conceito do corpo humano em relação às lesões medulares. Assim foram descobertas quais são as limitações e dificuldades dos cadeirantes na vida cotidiana.

A análise da Acessibilidade e Desenho Universal teve como objetivo atingindo a compreensão considerada sobre o conceito da mesma para que pudesse ser aplicada na cabine de audiometria de forma adequada, pois é um tema voltado para cadeirantes que vem sendo bastante explorado nos últimos anos para que possam ser oferecidos os mesmos direitos por lei que as pessoas sem necessidades especiais possuem.

Para chegar a Acessibilidade e Desenho Universal, foram utilizadas a Ergonomia e as medidas antropométricas para estudo, estimando e medindo de forma correta para garantir conforto e segurança para aqueles com necessidades especiais.

Para solucionar o problema da aplicação das medidas corretas respeitando as normas ergonômicas para usuários de cadeira de rodas, foi preciso utilizar as apostilas conhecidas como Associação Brasileira de Normas Técnicas baseada na acessibilidade (ABNT: NBR 9050) e outros referentes à mesma.

Acredita-se que embora o processo seja lento, futuramente todos os tipos de pessoas portadoras de deficiências receberão os equipamentos adequados de acordo com suas necessidades sem que aja o sentimento de exclusão da sociedade conceito descrito na cabine de audiometria que está se tornando acessível para todos com passar o tempo.

Por fim, quanto mais se estuda o projeto como um todo, mas em especifico à cabine de audiometria, mais se descobre sobre os objetos ou equipamentos e materiais que são utilizados nela para que funcione como um cubículo protegido de sons externos para não atrapalhar o exame auditivo no espaço interno tornando o aprendizado mais interessante.

\section{REFERÊNCIAS BIBLIOGRÁFICAS}

ACÚSTICA ORLANDI. Informações sobre cabines acústicas para audiometrias. Disponível em: <http://www.acusticaorlandi.com.br/duvida_ver.php?duvCodigo=6>. Acesso em: 04 de outubro de 2013.

ASSOCIAÇÃO SALVADOR. Faqs. Disponível em: <http://www.associacaosalvador.com/faqs/?alD=12>. Acesso em: 01 de abril de 2013.

BUENO, Silveira. Minidicionário da língua portuguesa. Ed. rev. e atual. São Paulo: FTD, 2000.

CAMBIAGHI, Silvana. Desenho Universal - métodos e técnicas para arquitetos e urbanistas. São Paulo: Ed. Senac São Paulo, 2007.

CARLETTO, Ana Claudia, CAMBIAGHI, Silvana. Desenho Universal: um conceito para todos. São Paulo: Instituto Mara Gabrilli, 2008, 38p. 


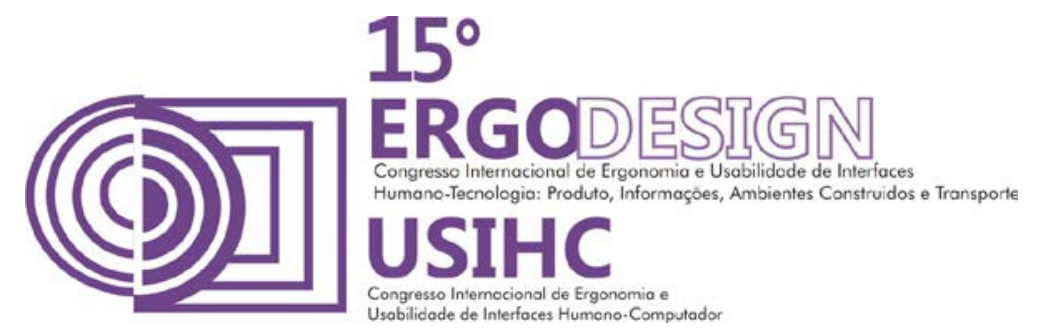

IBGE. Características gerais da população, religião e pessoas com deficiência. CENSO DEMOGRÁFICO 2010. Rio de Janeiro, 2010, p.1-215.

CENTRO AUDITIVO TEUTO BRASILEIRO. Equipamentos interacoustics. Disponível em: $<$ http://www.centroauditivo.com.br/novo/equipamentos-interacoustics-menu.php?equipamento=cabinesaudiometricas>. Acesso em: 18 de março de 2013.

CONSELHOS FEDERAL E REGIONAIS DE FONOAUDIOOGIA. Ambiente acústico em cabina/sala de teste - orientações dos conselhos de fonoaudiologia para o ambiente acústico na realização de testes audiológicos. Março 2010.

COSTA, E. C. Acústica Técnica. São Paulo: Edgard Blücher, 2003.

DUL, J.; WEERDMEESTER. Ergonomia Prática. 2a Ed. e ampl. São Paulo: Edgard Blücher, 2004.

LEONOR, Bruno B. F. Sistema de Acompanhamento de Avalições Audiométricas. Monografia (Especialização em Informática Empresarial) - Faculdade de Engenharia de Guaratinguetá. Guaratinguetá: Universidade Estadual Paulista, 2008. 39p

LÖBACH, Bernd. Design Industrial. São Paulo: Edgard Blücher, 2001.

MENDES, Tatiana. Dúvidas: TCC e Implante Coclear. Mensagem recebida por <tatianamendes@usp.br> em 14 de março de 2013.

MORAES, Ricardo. Um Novo Olhar sobre a Cidade. Recife: [s.l], 2004.

TILLEY, Alvin R.; ASSOCIATES, Henry. D. As Medidas do Homem e da Mulher - Fatores Humanos em Design. Porto Alegre: Bookman, 2005.

VIBRASOM. Produtos acústicos - Cabine Audiométrica. Disponível em: $<$ http://www.vibrasom.ind.br/produtos-acusticos/cabine-audiometrica-isolamento-acustico.php>. Acesso em: 25 de março de 2013. 